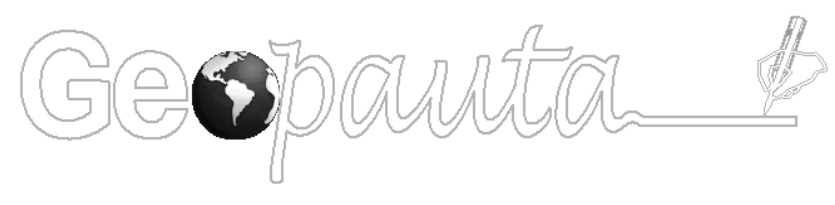

\title{
Santo Antônio de Jesus/BA e a institucionalização de bairros: os desafios do planejamento urbano em uma cidade média
}

\section{Santo Antônio de Jesus / BA and the institutionalization of neighborhoods: the challenges of urban planning in a medium-sized city}

\section{Santo Antônio de Jesus / BA y la institucionalización de barrios: los desafíos de la planificación urbana en una ciudad mediana}

\author{
James Amorim Araújo ${ }^{1}$ https://orcid.org/0000-0002-2561-4098 \\ Djalma Villa Góis ${ }^{2}$ https://orcid.org/0000-0002-6548-2552
}

\footnotetext{
${ }^{1}$ Departamento de Ciências Humanas, Campus V, UNEB. Santo Antônio de Jesus-Bahia-Brasil, E-mail: jaraujo@ uneb.br.

${ }^{2}$ Departamento de Ciências Humanas, Campus V, UNEB. Santo Antônio de Jesus-Bahia-Brasil, E-mail:. villa gois@ hotmail.com.
}

\section{Resumo}

Este artigo apresenta o trabalho realizado na cidade de Santo Antônio de Jesus na identificação, caracterização e proposição de divisão de bairros. A ausência de unidades socioespaciais intraurbanas oficializadas era, conjuntamente com a falta de um cadastro de logradouros, um dos maiores passivos urbanísticos da cidade reconhecida como média. Construímos um referencial teórico baseado em Lefebvre (1973), Certeau (2002), Seabra (2003; 2004), dentre outros teóricos. Neste sentido, nosso trabalho foi o de levantar, por meio de uma metodologia específica, as representações já consolidadas de bairros pela população a partir das toponímias de ruas e localidades e, dessa forma, propor uma divisão de bairros da cidade. Como resultado, chegamos à formulação de uma proposta de vinte e quatro bairros.

Palavras-chave: Bairro. cidade média. Planejamento urbano. Política.

\begin{abstract}
This article aims to present the work carried out in the city of Santo Antônio de Jesus in the identification, characterization and proposition of division of districts. The absence of formal intraurban socio-spatial units was, along with the lack of a register of public places, one of the city's highest urban planning liabilities recognized as average. For that, we constructed a theoretical framework based on Lefebvre (1973), Certeau (2002), Seabra (2003; 2004), among other theorists. In this sense, our work was to raise, through a specific methodology, the already consolidated

Geopauta, Vitória da Conquista ISSN: 2594-5033, V. 5, n.1, 2021, e6454
\end{abstract}

Este é um artigo de acesso aberto sob a licença Creative Commons da CC BY 
representations of neighborhoods by the population from the toponymy of streets and localities and, thus, propose a division of neighborhoods of the city. As a result, we came to the formulation of a proposal of twenty-four neighborhoods.

Keywords: Neighborhood. City average. Urban planning. Politics.

\section{Resumen}

Este artículo tiene por objetivo presentar el trabajo realizado en la ciudad de Santo Antônio de Jesús en la identificación, caracterización y proposición de división de barrios. La ausencia de unidades socioespaciales intraurbanas oficializadas era, junto con la falta de un registro de logradouros, uno de los mayores pasivos urbanísticos de la ciudad reconocida como media. Para ello, construimos un referencial teórico basado en Lefebvre (1973), Certeau (2002), Seabra (2003; 2004), entre otros teóricos. En este sentido, nuestro trabajo fue el de levantar, por medio de una metodología específica, las representaciones ya consolidadas de barrios por la población a partir de las toponímias de calles y localidades y de esa forma proponer una división de barrios de la ciudad. Como resultado, llegamos a la formulación de una propuesta de veinticuatro barrios.

Palabras clave: Barrio. ciudad media. Planificación urbana. La política.

\section{Introdução}

O trajeto que nos conduziu para esta reflexão aqui descrita parte da prática profissional aplicada a uma demanda social. A cidade de Santo Antônio de Jesus está localizada na porção sul da região do Recôncavo Baiano, distante $184 \mathrm{~km}$ da capital Salvador pelas BR 101 e 324. Seu tamanho populacional, medido pelo IBGE em 2010, já apontava um contingente próximo a 100 mil habitantes. Portanto, já poderia ser considerada uma cidade de porte médio ${ }^{3}$.

Apesar dos discursos e representações que buscam reiterar uma positividade no crescimento e urbanização da cidade, existem passivos urbanísticos consideráveis. Um exemplo disto diz respeito ao fato que até o ano de 2013 não havia um cadastro de logradouros urbanos. Além disso, poucos possuíam Código de Endereçamento Postal (CEP), para sermos mais claros, cerca de 300 logradouros de um contingente

\footnotetext{
${ }^{3}$ A definição de cidade média é bastante complexa porque não há consenso. Sposito (2014) afirma que "cidade média não é um conceito", mas apenas uma noção de medida de tamanho que é resultado da divisão do trabalho, entretanto, para dirimir questionamentos adotamos o critério do IBGE que estabelece uma cidade média como tendo entre cinquenta e quinhentos mil habitantes. Fonte: IBGE, 2017.
} 
desconhecido. Também não havia uma divisão oficial da sede do município em bairros, muito embora houvesse o reconhecimento popular, proveniente da própria história da cidade, de unidades geográficas com as características de bairros.

Tal situação fez que com a Associação Comercial e Empresarial de Santo Antônio de Jesus (ACESAJ) entrasse com uma representação junto ao Ministério Público Estadual (MPE) alegando prejuízos, uma vez que os Correios não tinham como entregar correspondências e encomendas. Foi a partir desse momento, ainda em 2013, que o curso de Geografia do Campus V da Universidade do Estado da Bahia (UNEB) foi convidado a participar das reuniões agendadas pelo MPE para encontrar uma solução. Depois de diversas tratativas e reuniões, a possível solução encontrada foi a constituição de um acordo do tipo Termo de Ajuste de Conduta (TAC) à Prefeitura Municipal. Pelo acordo, um convênio foi assinado entre a Prefeitura, a UNEB/Campus V e a Companhia de Desenvolvimento Urbano do Estado da Bahia $(\text { CONDER })^{4}$.

Pelo convênio, a UNEB ficou responsável de realizar o levantamento e cadastro de logradouros da cidade, propor uma divisão de bairros e de zonas urbanas e ainda um adensamento dos marcos geodésicos. Quanto à CONDER, responsabilizou-se pelo treinamento para a utilização do Sistema de Informações Geográficas (SIG), denominado de GEOPOLIS, pelo treinamento de campo para o preenchimento de um formulário denominado $\operatorname{PEDALITA}^{5}$ e a alimentação de uma Plataforma de dados geoespaciais de cidade, o GEOPOLIS. À Prefeitura Municipal coube assumir os custos financeiros e os encaminhamentos institucionais dos levantamentos e do próprio cadastro.

Depois de quatorze meses de intensos trabalhos (campo e laboratório), uma equipe composta por dois consultores técnicos e vinte e quatro estudantes do curso de Geografia levantou e cadastrou cerca de 1100 logradouros. Além disso, ficamos

\footnotetext{
${ }^{4}$ Convênio de cooperação técnica no 010/2013 PMSAJ/UNEB/CONDER.

${ }^{5}$ PEDALITA é um acrônimo criado pela CONDER para denominar um formulário de campo destinado a coletar dados das seguintes infraestruturas: Pavimentação, Eletrificação, Drenagem, Arruamento, Limpeza, Iluminação, Telefonia e Antenas de TV a cabo.
} 
responsáveis pela elaboração de propostas de divisão e zoneamento da sede municipal. Tais trabalhos foram sintetizados em três minutas de lei entregues à Prefeitura, que as submeteu em julho de 2015 à Câmara de Vereadores para apreciação e aprovação.

Destes trabalhos, destacamos como objeto de reflexão e análise o reconhecimento e a proposição de divisão oficial da cidade de Santo Antônio de Jesus em unidades socioespaciais intraurbanas, ou seja, em bairros. O principal motivo que incentivou a delimitação de bairros foi a inexistência de uma Lei Municipal e a necessidade de se estabelecer uma institucionalização, haja vista que para a codificação e endereçamento postal também se fazia necessária a existência formal destes.

Então, foi a partir destas questões práticas que uma problemática de pesquisa foi formulada. Esta problemática precisou ser reconhecida em sua complexidade e natureza, uma vez que não se tratava simplesmente de propor uma divisão de bairros, mas de reconhecê-los, individualizá-los e, finalmente, instituí-los. Assim sendo nos questionamos - como estabelecer uma divisão de bairros que seja uma expressão da vida das pessoas e, ao mesmo tempo, atenda às necessidades de planejamento? Quais desafios uma cidade média apresenta perante ao planejamento urbano e ao desenvolvimento socioespacial? Que autocrítica podemos fazer ao nosso papel de planejadores?

Neste artigo, objetivamos refletir sobre o percurso teórico-prático desenvolvido, as dificuldades com a elaboração da proposta, as consequências advindas da divisão em bairros e inclusive nosso papel social. Neste sentido, trata-se de uma reflexão a partir de uma encomenda, o que revela um caminho de uma pesquisa aplicada.

Entendemos que este artigo é uma contribuição para futuras discussões sobre o planejamento e gestão urbana de cidades médias, e os desafios a serem suplantados no sentido do desenvolvimento urbano. Portanto, além desta introdução, este artigo contém uma discussão teórica sobre o objeto em tela, a metodologia de trabalho, os resultados e a discussão e, por fim, as considerações finais. 


\section{Por uma ontologia geográfica de bairro e os limites do planejamento urbano com vistas ao desenvolvimento socioespacial}

O reconhecimento de unidades intraurbanas intituladas de bairros corresponde a um movimento que precisou unir uma reflexão teórica sobre a temática a uma problemática concreta. Afinal, o que estava em jogo não era a proposição tecnocrática de uma divisão artificial da cidade, mas antes tomar o que os próprios citadinos tinham como referenciais históricos de divisão da cidade. Esta problemática foi a que norteou o trabalho de identificação de bairros em Santo Antônio de Jesus.

Inicialmente fizemos um levantamento de algumas fontes teóricas sobre a temática, mas já tínhamos como referentes certas discussões empreendidas por Lefebvre (1973), Certeau (2002), Seabra (2003; 2004) e Carlos (2001) sobre os elementos mais importantes a serem considerados na discussão sobre bairros. Neste sentido, reconhece-se o recorte materialista das fontes teóricas. Por outro lado, é preciso enfatizar que estamos tratando de um arcabouço teórico que situa o marxismo ao résdo-chão, a partir de contribuições produzidas ao longo do século XX e que inclui a noção de vida cotidiana ${ }^{6}$.

Na literatura científica em geral, sobretudo internacional, a discussão de bairro é subsumida à de centralidade, de subcentros e redes, geralmente, em metrópoles. No Brasil, a grande parte dos estudos de bairro se tratam de estudos de caso, ou seja, o bairro é um suporte espacial para contextualizar um objeto de pesquisa. Um artigo de revisão de Bezerra (2011), no qual ele questiona como definir um bairro, conclui o autor que a discussão de Lefebvre (1973) e Certeau (2002) são as referências para este tema, mas por que são referenciais para a Geografia se não são geógrafos?

Bem, tanto Lefebvre quanto Certeau refletem sobre o bairro enquanto a uma espacialidade específica na cidade, ao tomar como ponto de partida as práticas cotidianas. Aqui talvez se encontre a explicação de porque são autores referenciais

\footnotetext{
${ }^{6}$ A vida cotidiana é a realidade vivida ao nível do cotidiano. Trata-se antes do plano imediato de vida, o que não exclui as dimensões mais abstratas. O cotidiano não é o banal, nem o insignificante. O cotidiano é o plano dos conflitos, da negociação, das ambiguidades, da alienação e da desalienação. (Ver para isto Critique de la vie quotidienne III (1981) de Henri Lefebvre).
}

Geopauta, Vitória da Conquista ISSN: 2594-5033, V. 5, n.1, 2021, e6454 
para a discussão de bairro, pois partem do cotidiano e suas práticas. Por práticas cotidianas Seabra (2003) destaca aquelas rotineiras como ir ao trabalho e retornar para casa, ir à escola, encontrar amigos na padaria ou na praça, ir à feira, etc. Com efeito, ao se correlacionar bairro às práticas cotidianas os autores acima desvelam uma relação espaço-tempo.

A relação espaço-tempo produz uma tessitura histórica cotidiana comum aos praticantes, expressa no reconhecimento do outro como semelhante, mesmo em sua alteridade. A constituição dessa tessitura cotidiana é um indicador da apropriação coletiva da cidade. Logo, o bairro, enquanto espacialidade, ele vem da história, isto é um fato histórico concreto cuja singularidade é um aspecto relevante. Esta interpretação envolve um acúmulo de tempo diferencial ${ }^{7}$.

Também é importante destacar outra característica levantada por Lefebvre (1973), acerca das distâncias socioespaciais para se reconhecer um bairro. Este tende a suplantar pela convivência diária tudo que é considerado distante, logo, isto coloca um limite têmporo-espacial na escala de metros. Corroborando com esta assertiva de Lefebvre, Certeau (2002) acrescenta que o bairro negocia o plano do privado (a casa) com o plano do público (a rua), ao criar um dispositivo prático-sensível ${ }^{8}$ de mediação. Em resumo, as práticas cotidianas em uma cidade são dialetizadas pelo bairro.

Contudo, até aqui a discussão gravitou em torno do bairro como um ente ontológico da cidade, isto é, ele vem da própria história concreta das pessoas e de sua relação com o espaço. No entanto, quando a vida cotidiana deixa de acontecer, quando o esvaziamento e o estranhamento ${ }^{9}$ tomam o lugar das relações de proximidade e identidade por conta de relações abstratas ${ }^{10}$, o que acontece com o bairro?

\footnotetext{
${ }^{7}$ O tempo diferencial é um tempo eminentemente histórico/geracional. Sua leitura é geralmente sintetizada na discussão de memórias.

${ }^{8}$ Prático-sensível porque é formal, tangível.

${ }^{9} \mathrm{O}$ que seria estranhamento? Carlos (2001) nos diz o seguinte: "O estranhamento provocado pelas mudanças no uso do espaço e por uma nova organização do tempo na vida cotidiana coloca o indivíduo diante de situações mutantes inesperadas. A constante renovação/transformação do espaço urbano por meio das mudanças morfológicas da metrópole produz transformações nos tempos urbanos da vida, nos modos e tempos de apropriação/uso dos espaços públicos, por exemplo, aquele da rua. A cidade aparece como exterioridade; ela está fora do indivíduo, apontando para uma condição de alienação." (p.33)

10 Relações abstratas são mediadas e estruturadas por um equivalente terceiro. Na sociedade capitalista, o equivalente geral das relações sociais é o dinheiro.
}

Geopauta, Vitória da Conquista ISSN: 2594-5033, V. 5, n.1, 2021, e6454 
Esta questão foi verificada por Carlos (2001) quando demonstrou a produção do estranhamento na metrópole recortada por operações urbanas que tendem a destruir a convivência cotidiana das pessoas. Com efeito, é possível que um bairro deixe de existir enquanto espacialidade (espaço social) e, no entanto, continue a existir no discurso dos planejadores públicos e privados (representação do espaço). Esvazia-se seu conteúdo histórico, mas mantém-se a representação da sua existência como se tudo fora tal como antes. Apesar de este fenômeno ter sido reconhecido em uma grande cidade ou metrópole, isto não significa que não possa ocorrer em uma cidade média. A questão é saber como o estranhamento ocorre em uma cidade média e quais diferenças podem ou não existir em relação a uma metrópole.

Esta reflexão parte de um fato, a produção espacial, cada vez mais comum, de condomínios que buscam difundir a representação de uma "vida completa" em um bairro planejado. Mas como planejar a vida cotidiana? Como definir a priori como deve ser a vida de bairro? Quem planeja e para quem? Questões primeiras que anunciam as contradições do devir de bairro em um contexto social dominado pela forma mercadoria.

O ponto a ser destacado se refere ao movimento acumulativo das contradições da sociedade capitalista às formas espaciais destinadas ao habitar. Por exemplo, Seabra (2004) quando reflete a segregação socioespacial na metrópole, identifica os chamados "territórios de uso" que autossegregam uma parcela da população. O sentido destes territórios de uso é separar (segregar) do convívio cotidiano os abastados das classes pobres ${ }^{11}$. Tal fenômeno também atinge as cidades médias brasileiras, inclusive a cidade de Santo Antônio de Jesus ${ }^{12}$. Logo, isto cria empecilhos

\footnotetext{
${ }_{11}$ A literatura científica brasileira tende a estabelecer uma diferença entre periferia e subúrbio. Por exemplo, na discussão de territórios de uso, frutos da autossegregação das classes médias e altas, usa-se o termo subúrbio para descrever seus habitats. Por outro lado, quando os territórios de uso são de classes populares usa-se o termo periferia. Tal distinção não ecoa na literatura científica internacional como a inglesa ou a francesa.

${ }^{12}$ No interessante trabalho de mestrado de Antônio Andrade Mota intitulado "A inserção dos condomínios fechados no espaço urbano de Santo Antônio de Jesus: apropriação da natureza, produção do espaço e legislação (2009), o autor afirma, categoricamente, que "Os condôminos mantém muito pouca relação com o entorno onde estão inseridos os seus condomínios fechados (...) O uso da rua é dispensado, a rua é vista como um local perigoso e pouco atrativo, os espaços públicos e de livre acesso são desprezados." (p. 102).
}

Geopauta, Vitória da Conquista ISSN: 2594-5033, V. 5, n.1, 2021, e6454 
práticos no reconhecimento e aceitação de bairros no plano prático, uma vez que o convívio é esvaziado.

A reflexão ora empreendida sobre o estatuto ontológico de bairro não pode ser desvinculada de uma política de planejamento urbano. Existe uma ampla discussão a respeito do planejamento urbano no Brasil sob um viés crítico. Essa discussão crítica destaca, sobretudo, o caráter ideológico dos chamados planejadores urbanos e a finalidade de seus planos. Por exemplo, Villaça (2004) destaca a relação entre os planejadores e o mercado imobiliário que acaba sempre condicionando a elaboração de planos diretores tecnocráticos e distantes da participação popular. Também a estudiosa das questões urbanas, a Profa. Raquel Rolnik (1994), reitera esses vieses tecnocráticos do planejamento urbano que conflitam com as demandas populares.

As demandas sociais relativas ao direito à cidade foram, em parte, aceitas na formulação da política urbana na Constituição Federal de 1988 e, mesmo depois, no período entre a nova Constituição Federal e a promulgação da Lei 10527/2001, conhecida como Estatuto das Cidades. Contudo, as demandas mais urgentes nunca foram de fato solucionadas, na realidade, o pacto firmado em torno dos artigos 182 e 183 da Constituição Federal colocou nas mãos dos municípios a responsabilidade no planejamento urbano por meio da elaboração e aplicação de Planos Diretores ou Planos Diretores de Desenvolvimento Urbano (PDDU).

Já existem análises sobre os PDDUs pós Estatuto das Cidades. E, em relação às cidades médias e aquelas acima de 20 mil habitantes, a crítica reiterada (SANTOS JUNIOR \& MONTANDON, 2011) recai sobre os planos diretores que são meras repetições de tantos outros e, por isso, vazios do conteúdo essencial - o planejamento, por isso, a crítica de Henri Lefebvre ao planejamento enquanto prática profissional/social. O contexto no qual o planejamento ocorre é político, neste sentido, há uma agenda definida por interesses político-econômicos. Fato que conduz os urbanistas a uma prática restrita, seja através de um "formalismo (adoção de modelos que não têm nem conteúdo, nem sentido) ou seja por meio de um estetismo (adoção de modelos antigos pela sua beleza) (LEFEBVRE, 2001, p. 24). No fundo, o planejamento 
ou planificação espacial "tem uma função organizadora da economia, a economia moderna cada vez mais toma forma espacial (...) e o domínio do espaço tende a tornálo mais eficiente." (DAMIANI, 1999, p. 56).

No caso deste trabalho, o reconhecimento e a instituição de bairros aconteceram fora de um contexto de revisão do plano diretor municipal, pelo fato da demanda ter se originado em um momento anterior ao de uma revisão do plano diretor de Santo Antônio de Jesus. Tal especificidade nos possibilitou uma maior "liberdade" porque vinculou nossa tarefa distante da agenda de outros agentes sociais como aqueles dos empreendedores imobiliários. Por outro lado, há limites porque o contexto de demandas também incluía além da própria população, os políticos e empresários ansiosos pela solução de um problema prático - a não codificação postal de logradouros e a não definição de bairros. Este problema é recorrente nas cidades médias e pequenas e revela o atraso no desenvolvimento urbano do país.

Contudo, nossa atuação frente ao complexo contexto histórico ainda incluía mais um agente social com o qual trabalhamos incessantemente, trata-se da CONDER. Por ser um órgão estadual de planejamento urbano, a CONDER já trabalhava com bairros, por isso, utiliza elementos de reconhecimento baseados em equipamentos urbanos de uso comum, a exemplo de praça, escola, posto de saúde, presentes em uma espacialidade identificada por uma mesma toponímia.

Dessa forma, ao cotejarmos nossas referências teóricas aos procedimentos técnicos de reconhecimento de bairro, da CONDER, chegamos a um meio termo sobre as características reconhecidas como "essenciais" de um bairro expressas nos seguintes elementos:

I- possuir uma densidade histórica e relativa autonomia no contexto urbano, ou seja, vida de bairro;

II - incorporar as noções de identidade e pertencimento dos moradores que o constituem; e, 
III - utilizar os mesmos equipamentos e serviços comunitários (escola pública, posto de saúde, transporte público ou similar e possua sistema viário organizado em torno de, pelo menos, uma via coletora).

É claro que se trata de um equacionamento prático de uma discussão teórica profunda, pois, precisávamos definir o escopo do trabalho antes de ir ao campo. É certo que podíamos acrescentar outros elementos, no entanto, os três elementos acima arrolados se mostraram suficientes para a realidade socioespacial da cidade de Santo Antônio de Jesus.

Finalmente, qual seria a finalidade de institucionalização de bairros e codificação postal? A resposta para esta pergunta está justamente no que se denomina no meio acadêmico de desenvolvimento socioespacial. Como adverte Souza (2011) desenvolvimento socioespacial ao nível urbano não significa urbanização, porque este processo é apenas de crescimento e modernização, contudo, para que haja desenvolvimento os termos são outros e estão ligados à melhoria da qualidade de vida e de justiça social ${ }^{13}$.

A institucionalização de bairros e de códigos postais em logradouros é uma ação que responde ao desenvolvimento socioespacial à medida que os termos de identidade de lugar passam a ser reconhecidos. Não há nada mais terrível do que morar em um lugar e este não ser sequer identificável ou acessível.

Logo, foi neste contexto político-conceitual que enquadramos este trabalho. Na seção seguinte, explicitaremos os procedimentos metodológicos do trabalho realizado, assim como uma análise crítica dos resultados.

\section{Procedimentos metodológicos}

A realização deste trabalho exigiu a consecução de várias etapas e procedimentos. Desde a primeira até a última foram coletados dados acerca da identificação dos bairros, de seus limites e pontos de conflito. A coleta básica de

\footnotetext{
13 Justiça social é uma noção que derivada de um debate no âmbito do direito. Ela significa que um cidadão é um ser de direitos, dentre eles, os fundamentais (moradia, trabalho, alimentação, saúde).
}

Geopauta, Vitória da Conquista ISSN: 2594-5033, V. 5, n.1, 2021, e6454 
informações sobre os bairros aconteceu concomitante ao levantamento dos logradouros da cidade, ao todo a equipe precisou de quinze meses ininterruptos de trabalho ${ }^{14}$. O formulário utilizado pelos estagiários, no campo, permitia registrar a indicação da espacialidade reconhecida como bairro a partir de entrevista feita aos moradores.

Feita a coleta de dados em campo, os mesmos foram lançados no Sistema de Informações Geográficas (SIG) denominado GEOPOLIS pertencente à CONDER. Foi preciso que todas as informações relativas aos logradouros fossem lançadas para permitir também a identificação de cada provável bairro no qual o logradouro pertencia. Após este trabalho de gabinete, foi possível gerar mapas impressos no formato A0 (zero) de toda a cidade de Santo Antônio de Jesus.

A etapa seguinte se caracterizou pela realização de diversas reuniões entre a equipe técnica da UNEB, representantes dos Correios e quadro técnico da Prefeitura Municipal com notório saber sobre as espacialidades intraurbanas da cidade. Desta forma, foram discutidos diversos aspectos relativos aos bairros como história de constituição, denominação, localização, limites e pontos de conflito. E, com efeito, a equipe de trabalho precisou retornar diversas vezes ao campo para dirimir pontos de conflito ou informações imprecisas.

Sanados todos os pontos conflituosos ou de informação imprecisa, a equipe retornou ao trabalho de gabinete (Laboratório de Geoprocessamento) para realimentar o GEOPOLIS. Após isto, foi gerada uma imagem digital dos bairros da cidade em formato TIFF. Finalizada a etapa gráfica, demos início aos trabalhos de elaboração de memoriais descritivos dos limites de cada bairro. Este trabalho foi muito extenuante devido a minuciosidade que a descrição dos limites exige.

De posse da imagem digital e dos memoriais descritivos dos bairros, a etapa seguinte foi realizar mais uma rodada de reuniões e audiências públicas. Assim, apresentamos a divisão de bairros à CONDER, à Secretaria de Planejamento da

\footnotetext{
${ }^{14} \mathrm{O}$ trabalho de campo para a coleta de dados e o retrabalho de laboratório iniciaram em março de 2014 e findaram em junho de 2015.
}

Geopauta, Vitória da Conquista ISSN: 2594-5033, V. 5, n.1, 2021, e6454 
Prefeitura Municipal de Santo Antônio de Jesus, aos Correios e ao Ministério Público Estadual, os quais fizeram correções pontuais em alguns polígonos. Feito isto, a etapa seguinte foi apresentar a divisão de bairros em audiência pública na Câmara Municipal, com a finalidade de tornar o trabalho conhecido pela população. Ouvidas todas as críticas e sugestões, as quais foram incorporadas ao trabalho, foi dada por encerrada a elaboração da proposta de divisão de bairros e apresentada sob a forma de uma minuta à Prefeitura Municipal. Esta, por sua vez, submeteu à Câmara de Vereadores em setembro de 2015.

\section{Os resultados alcançados e sua discussão}

Ao todo, foram reconhecidos e instituídos, por lei ${ }^{15}, 24$ (vinte e quatro) bairros assim identificados: Amparo, Andaiá, Barro Vermelho, Cajueiro, Calabar, Campo do Governo, Casco, Centro, Distrito Industrial, Ernesto Melo, Irmã Dulce, Maria Preta, Nossa Senhora das Graças, Praia do Dendê, Quitandinha, Renato Machado, Salgadeira, Santa Madalena, Santa Rita, Santa Terezinha, São Benedito, São Cristóvão, São Paulo e Sobradinho, conforme mapa 1.

Mapa 1-Proposta final de divisão de bairros da cidade de Santo Antônio de Jesus-2015

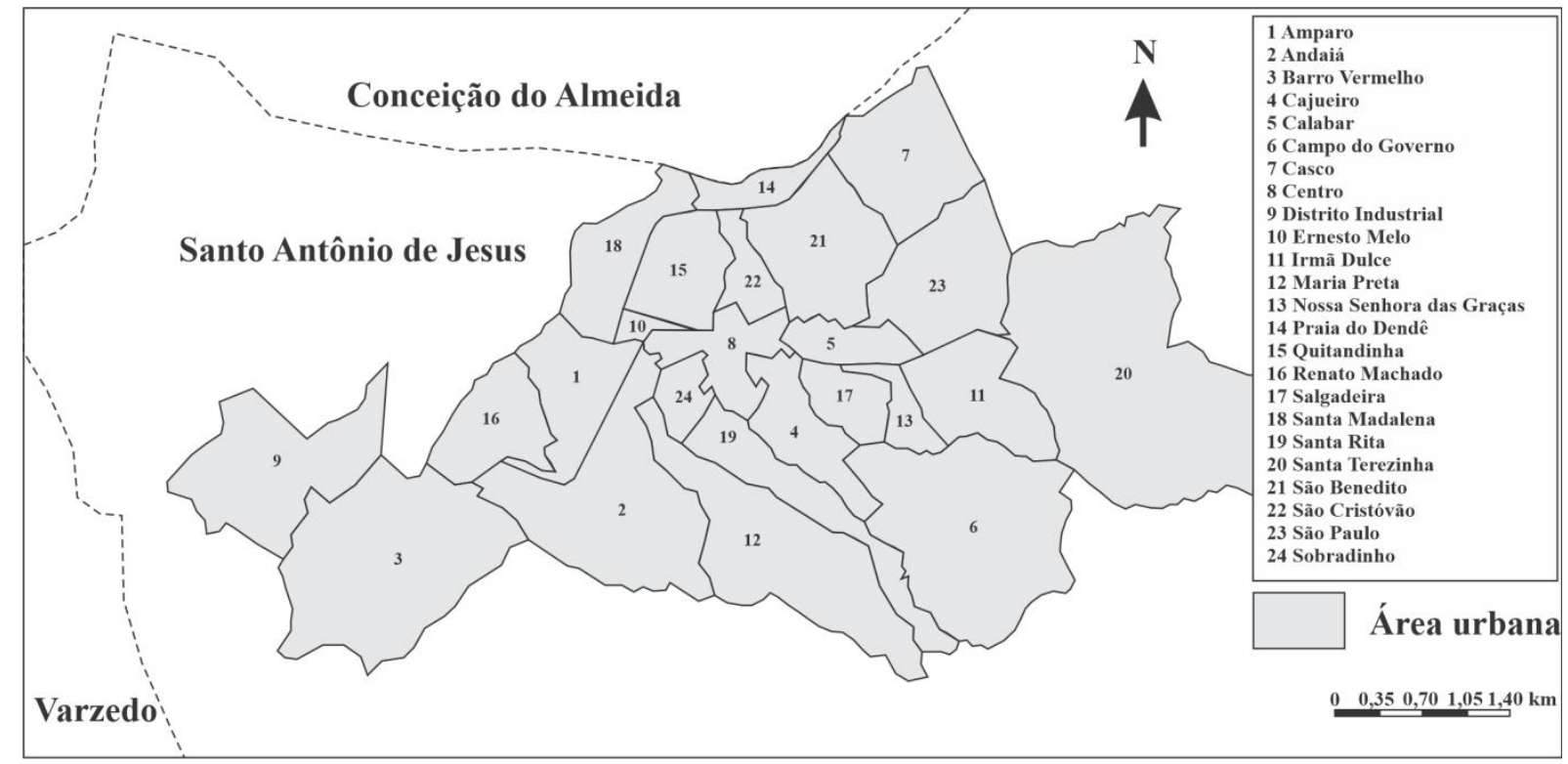

Fonte: Conder (2015)

\footnotetext{
${ }^{15}$ Lei Municipal no 1299 de 09 de novembro de 2015. Institui a delimitação de bairros da sede do Município de Santo Antônio de Jesus.
} 
Estes 24 bairros foram subdivididos por zonas urbanas, a saber: zona central, norte, sul, leste e oeste, mapa 2. Ficou ainda definido que a cada sete anos, a partir da vigência da lei, revisões e atualizações sejam feitas, caso seja necessário. Além disso, se novos bairros forem reconhecidos, os seus limites e as respectivas descrições de suas poligonais deverão ser efetuados graficamente, além é claro, de um memorial descrito. Mapa 2- Proposta final de divisão de zonas da cidade de Santo Antônio de Jesus-2015

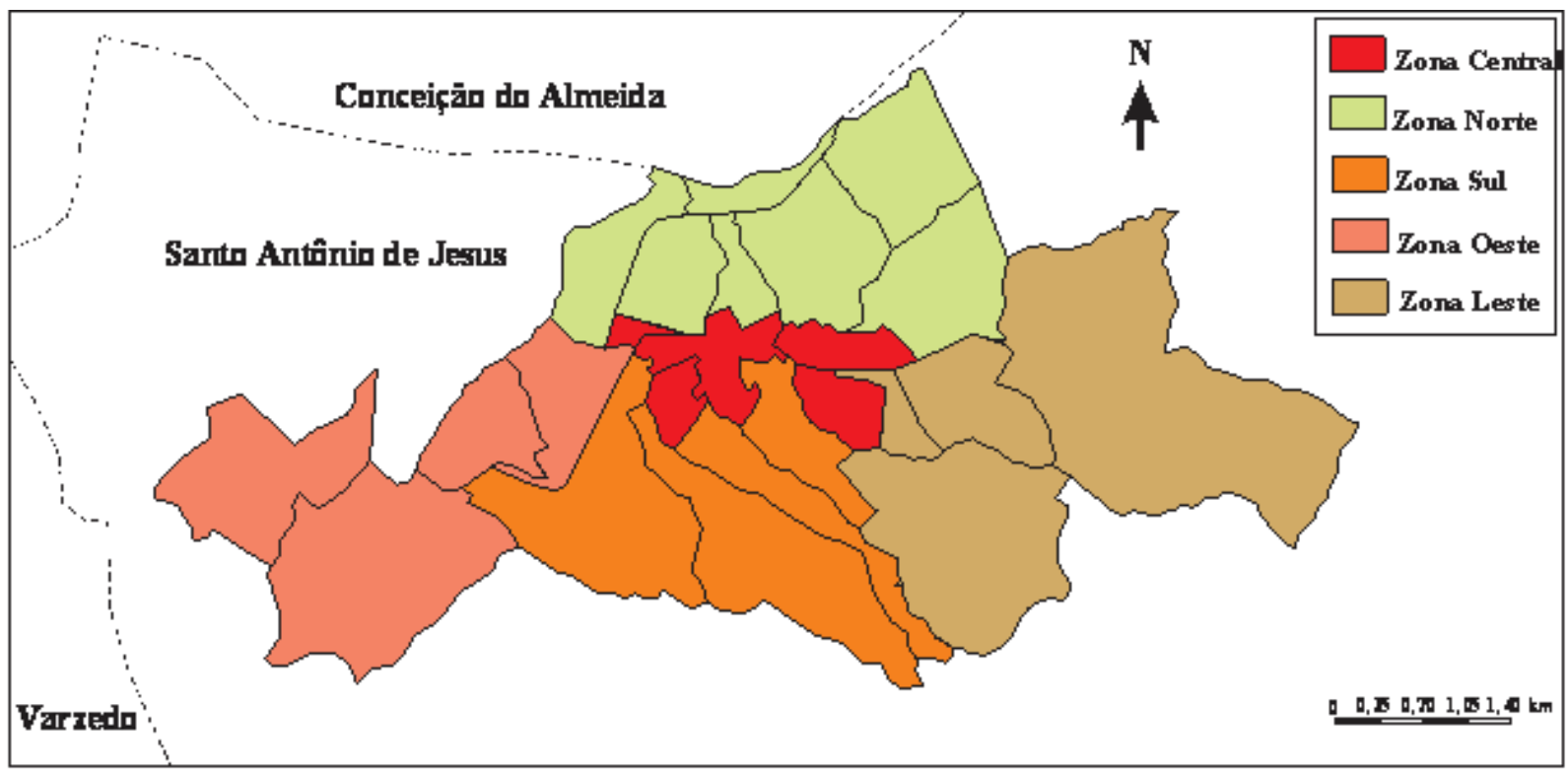

Fonte: Conder/Uneb (2015).

Estas propostas de divisão de bairros e de zonas urbanas revelaram uma constatação óbvia. A área urbanizada da cidade de Santo Antônio de Jesus cresceu, o que significou um aumento significativo em relação à área total do município. Em termos exatos, a mancha urbana atingiu, aproximadamente, $32 \mathrm{~km}^{2}$ em relação à área do município de $268 \mathrm{~km}^{2}$ (IBGE). Este redimensionamento de tamanho só confirma a acelerada urbanização do município se compararmos com o tamanho da mancha

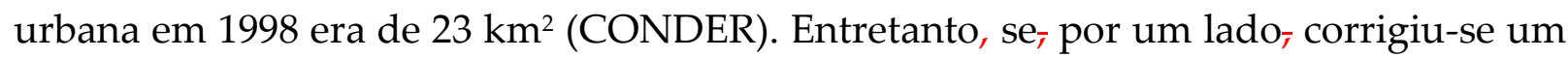
problema para a administração pública porque as áreas de expansão urbana foram reconhecidas, por outro lado, colocou-se pressão sobre as áreas agricultáveis e de preservação ambiental. 
Carta imagem 1- Proposta de Bairro- Calabar - cidade de Santo Antônio de Jesus-BA

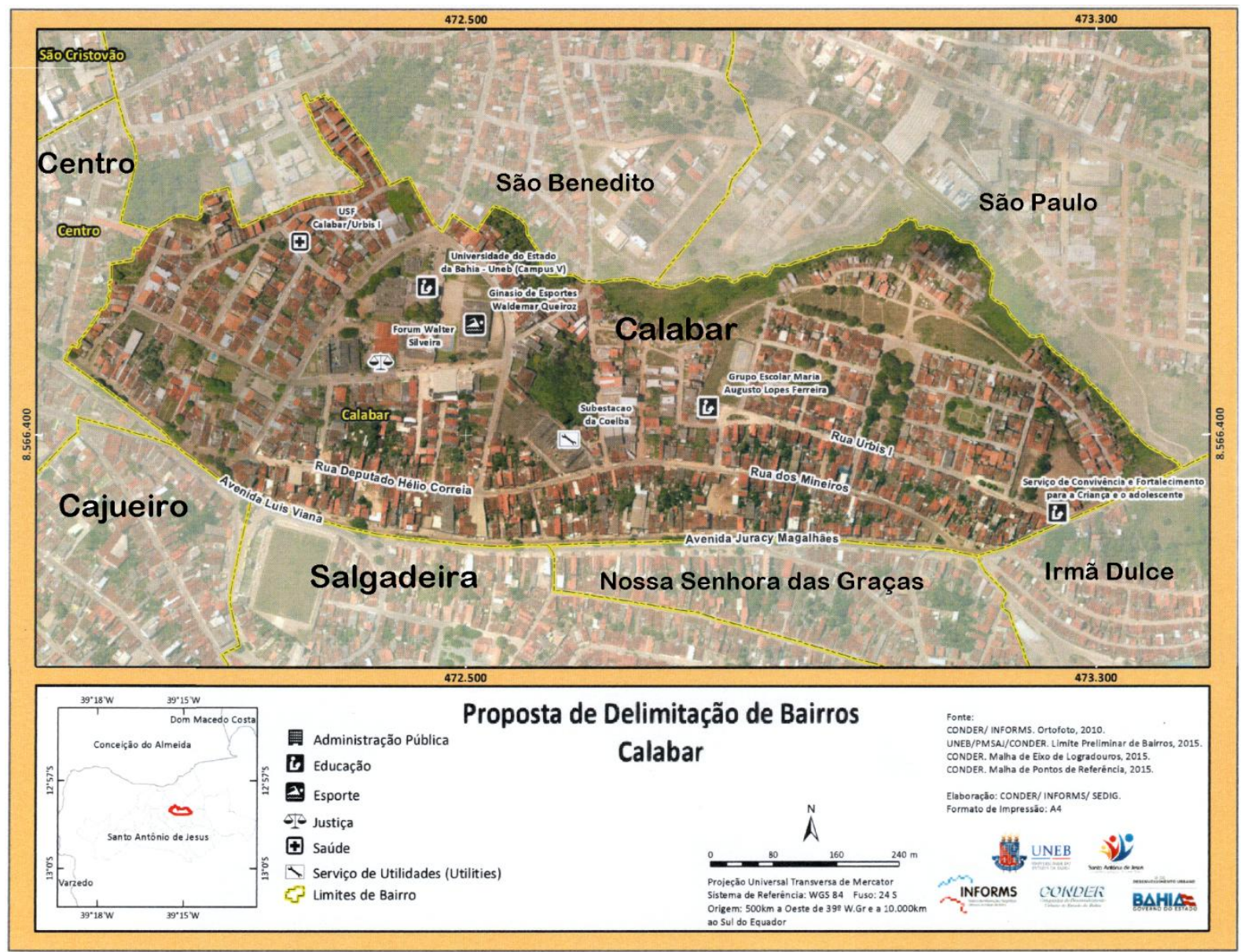

Fonte: Conder/Uneb (2015).

É importante destacar ainda os principais problemas enfrentados durante o reconhecimento dos bairros, dentre eles destacamos: os conjuntos habitacionais populares, principalmente, as URBIS I, II e III que sempre foram vistos como bairros pelos moradores; a recuperação de espacialidades antigas subsumidas, sobretudo, por loteamentos ou condomínios direcionados à classe média; a constituição de bairros "artificiais"; as espacialidades que não atendiam todos os requisitos estabelecidos para serem considerados bairros; e, o limite urbano-rural.

Sobre os conjuntos habitacionais a representação mais aceita pela população moradora é de que eles em si constituíam bairros próprios, no entanto, na visão dos técnicos dos Correios os conjuntos se inseriam em bairros que já existiam anteriormente. Após várias reuniões e visitas a campo passamos a concordar com os técnicos dos Correios porque vários serviços de uso coletivo (saúde, educação etc.) se encontravam fora dos conjuntos habitacionais. É importante frisar que as toponímias 
dos conjuntos foram mantidas justamente para minimizar os conflitos práticos advindos da decisão. Um exemplo desta decisão se refere ao Conjunto Urbis I que foi reconhecido como pertencente ao bairro do Calabar (Carta imagem 1).

O próprio bairro do Calabar é um caso emblemático de recuperação de espacialidade subsumida. Durante anos, por conta de uma produção espacial que incluiu um loteamento para uma parcela da classe média e outros imóveis da administração pública e de serviços coletivos, a espacialidade precedente denominada de Calabar foi sendo "apagada". No seu lugar, ora se dizia que o bairro pertencia ao centro ou que ali era o Jardim Brasil, denominação dada ao loteamento. Contudo, na pesquisa de campo os estagiários foram colhendo diversos testemunhos de moradores que afirmavam que ali era o antigo bairro do Calabar. Também havia como prova disto o fato de muitos logradouros com nomes que remetiam ao antigo nome do bairro.

Com efeito, durante as reuniões técnicas quando colocamos esta questão aos representantes dos Correios, estes também acabaram por concordar com esta posição, logo, acabamos por tomar a decisão de recuperar a toponímia original. Outra consideração analítica diz respeito a alguns bairros não se adequaram a todos os critérios estabelecidos. Neste caso prevaleceu o fato de que já faziam parte como topônimos e da memória urbana, um exemplo se refere ao bairro Ernesto Melo que não possui todos os equipamentos e serviços coletivos, como definidos teoricamente porque possui uma extensão territorial muito exígua, vide (Carta imagem 2) 
Carta imagem 2- Proposta de Bairro- Ernesto Melo - cidade de Santo Antônio de Jesus-BA

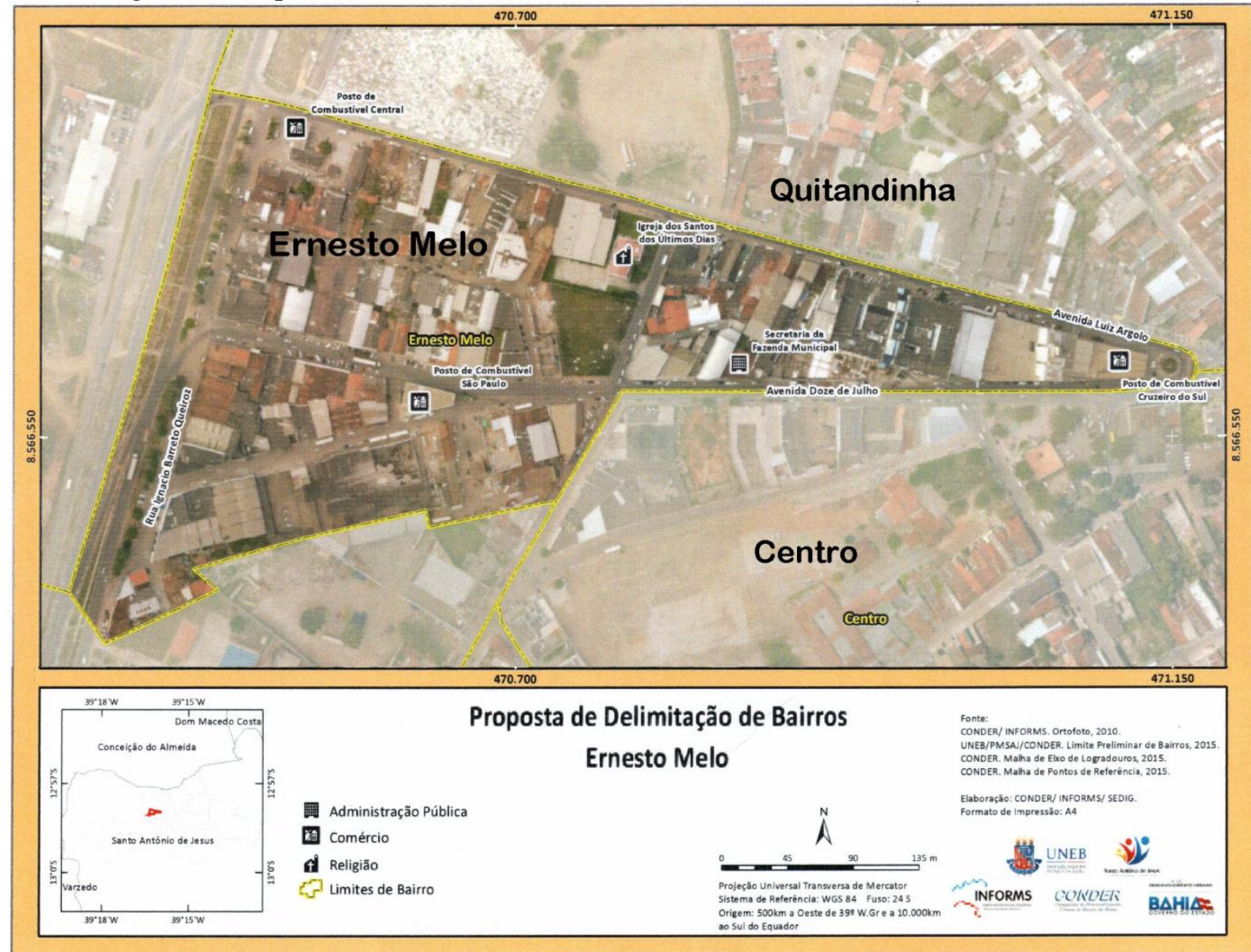

Fonte: Conder/Uneb (2015).

A constituição de espacialidades artificiais, isto é, sem as características apontadas na definição de bairro, foi um dos problemas com os quais a equipe teve que lidar. O fenômeno está relacionado, basicamente, aos condomínios destinados à classe média que se autossegrega, tal como Seabra (2004) denominou de território de uso. Por exemplo, para a definição do bairro Santa Rita foi necessário negociar com diversos atores sociais no sentido de que eles aceitassem primeiro que seu condomínio não era um bairro. Isto implicou em uma quase ausência do critério de vida de bairro e de identidade, neste sentido uma questão importante a ser feita é a seguinte - um território de uso pode ser reconhecido como bairro no sentido da discussão que fizemos neste trabalho? A resposta é não! O bairro vem da história, o "bairro" Santa Rita é baseado no estranhamento e segregação, portanto, é um território. A Figura 5 apresenta a proposta para o referido bairro. 
Outra consideração analítica se trata da questão dos limites de bairros frente ao que não é urbano. Dessa forma, estes limites foram estabelecidos tomando por base outros elementos não ligados à ambiência urbana, como um riacho ou uma estrada vicinal.

Carta imagem 3- Proposta de Bairro- Santa Rita - cidade de Santo Antônio de Jesus-BA

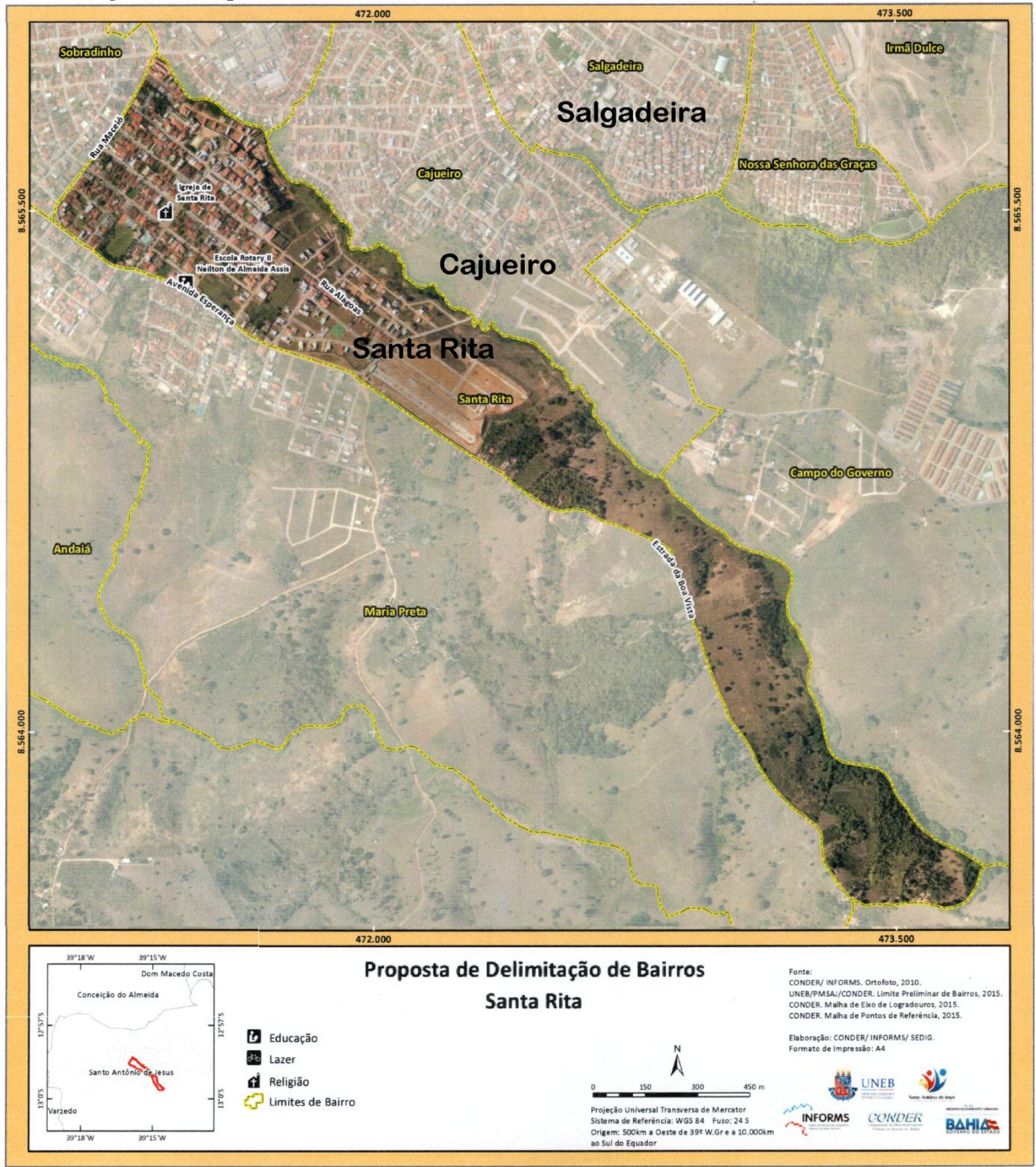

Fonte: Conder/Uneb (2015). 
Na Carta Imagem 3, podemos observar que os limites dos bairros Santa Rita e Maria Preta são contíguos à zona rural, então, de fato estamos em uma área de contato urbano-rural. Tal constatação projeta várias questões que aparentemente não são relevantes, mas de fato são, por exemplo, cabe ao município definir o que é urbano por lei, mas quando não faz isto, como fica a caracterização de bairros? Também a cobrança de impostos territoriais (urbano ou rural) depende de uma definição dos limites urbano-rural, porém, quando esta definição inexiste os moradores de áreas de contato podem sofrer com uma dupla cobrança de impostos.

O limite cidade-campo é também um desafio teórico-empírico em uma cidade média. Em Santo Antônio de Jesus, percebemos que se construiu uma representação negativa do campo e do modo de vida rural, e isto se reflete até no estabelecimento dos limites da cidade. Nas cercanias da cidade, mesmo quem mora em pequenas fazendas ou chácaras não se vê mais como morador do campo. Enfim, esta área de contato urbano-rural em uma cidade média suscita muitas questões.

Por fim, mas não menos importante cabe-nos uma análise do papel institucional no planejamento e desenvolvimento urbano. Apesar de todo o trabalho desenvolvido, o resultado prático para a população só se realizou parcialmente em 2019, quando os novos códigos postais, a denominação oficial de ruas e a divisão de bairros foram divulgados. Contudo, a Prefeitura Municipal e a ACESAJ não emplacaram os logradouros conforme o que se pactuava no TAC, logo, todo o trabalho desenvolvido não se efetivou na vida do cidadão comum como havia sido planejado.

\section{Considerações finais}

Quais considerações podemos fazer sobre o trabalho desenvolvido? Haveria particularidades em Santo Antônio de Jesus, enquanto uma cidade média, que resultem em diferenças no planejamento urbano ou isto é uma condição comum das cidades do interior do país? 
Uma primeira consideração a ser feita ao trabalho é justamente a reflexão teórica. É fato que existe sobre a temática um acúmulo de conhecimento, contudo, parte se refere a uma grande cidade ou mesmo uma metrópole. Neste sentido, a realidade encontrada em uma cidade média destoa de muitos parâmetros das teorias sobre o urbano. Por exemplo, nem sempre é possível encontrar todos os equipamentos urbanos em um bairro, mas isso não significa que ele não existe. Cabe, portanto, às ciências do espaço (Geografia, Urbanismo, Sociologia urbana etc.) avançarem na reflexão de características particulares dos bairros em cidades médias.

Outra consideração se refere à urbanização de Santo Antônio de Jesus. Enquanto processo, podemos afirmar que se acelerou nos últimos anos com a produção e expansão da malha urbana, contudo, o tipo de urbanidade produzida é "espraiada". Portanto, a tão presente contiguidade da malha urbana presente em metrópoles não se realiza da mesma maneira. Os "vazios" da malha urbana revelam um processo de fragmentação do uso do solo urbano que merece ser comparado ao de outras cidades médias, pois talvez revele um padrão de urbanização. Então, estamos diante de um fenômeno que remete à renda fundiária e à lógica de mercado que precisa ser melhor compreendido em cidades médias.

Uma autocrítica se faz necessária. É óbvio que assumimos o papel de “tecnocratas de boa vontade" como Lefebvre (2001) já indicara. É preciso não perder de vista que os ditos benefícios que a instituição oficial de bairros traria não se restringiria apenas aos citadinos, mas também à própria Prefeitura Municipal que passaria a contar um elemento para aperfeiçoar sua base de impostos territoriais. Ademais, por se tratar de uma encomenda, este trabalho foi monitorado pelo MPE e demais parceiros, fato que gerou uma tensão institucional. Por outro lado, este trabalho também nos fez entender os limites e desafios para se pensar e planejar uma cidade média e o complexo "jogo político" que circunscreve a ação social.

Entendemos o que acontece na cidade de Santo Antônio de Jesus não se trata de um caso isolado. Na realidade, só confirma a regra de como o planejamento urbano é usado pelo "jogo político" conjuntural. Em uma gestão é valorizado, em outra, 
simplesmente não interessa. Por isso, o desafio do desenvolvimento socioespacial em cidades médias e pequenas seja talvez maior do que em uma metrópole. Parece contraditório isto que afirmamos, mas a dimensão política é um componente de "peso" quando se propõe qualquer ação de planejamento e melhoria da qualidade de vida da população.

E, como última e não menos importante consideração, reiteramos que o trabalho de reconhecimento e instituição de bairros nos trouxe uma compreensão sobre o papel fundamental que a ausência de urbanidade pode acarretar na vida da população, sobretudo, a mais pobre, mas também nos fez mais uma vez reafirmar a luta pelo direito à cidade como uma condição sine qua non de cidadania e desenvolvimento socioespacial.

\section{Referências}

BEZERRA, Josué Alencar. Como definir um bairro? Uma breve revisão. In: Geotemas. Pau dos Ferros/Rio Grande do Norte, v. 1, n.1, p. 21-31, jan/jul., 2011.

BRASIL. Lei 10527, de 10 de julho de 2001 (Estatuto das Cidades). Publicada no Diário Oficial da União, Brasília, DF, 10 jul. de 2001.

BRASIL. Constituição da República Federativa do Brasil. 1988. Publicada no Diário Oficial da União, Brasília, DF, 05 out. de 1988.

CARLOS, Ana Alessandri. Fani. Espaço-tempo na metrópole: a fragmentação da vida cotidiana. São Paulo: Contexto, 2001.

CERTEAU, Michel de, GIARD, Luce \& MAYOL, Pierre. A invenção do cotidiano 2 habitar, cozinhar. 4 ed. Petrópolis, RJ: Vozes, 2002.

DAMIANI, Amélia Luisa. As contradições do espaço: da lógica (formal) à (lógica) dialética, a propósito do espaço. In: DAMIANI, Amélia Luisa, CARLOS, Ana Fani Alessandri, SEABRA, Odette Carvalho de Lima. O espaço no fim do século: a nova raridade. São Paulo: Contexto, 1999.

IBGE. Classificação e caracterização dos espaços rurais e urbanos do Brasil: uma primeira aproximação. Rio de Janeiro: FIBGE, 2017. 
LEFEBVRE, Henri. O direito à cidade. São Paulo: Centauro, 2001.

LEFEBVRE, Henri. Do rural ao urbano. 2 ed. Barcelona: Península, 1973.

MOTA, Antônio Andrade. A inserção dos condomínios fechados no espaço urbano de Santo Antônio de Jesus: apropriação da natureza, produção do espaço e legislação. (Dissertação de Mestrado). Programa de Pós-graduação em Geografia da Universidade Federal da Bahia, 2009.

ROLNIK, Raquel. Planejamento Urbano nos Anos 90: novas perspectivas para velhos temas. In: Luís Ribeiro; Orlando Júnior. (Org.). Globalização, Fragmentação e Reforma Urbana - o futuro das cidades brasileiras na crise. Rio de Janeiro: Civilização Brasileira, 1994.

SANTOS JUNIOR, Orlando Alves dos; MONTANDON, Daniel Todtmann (Orgs.). Os planos diretores municipais pós-estatuto da cidade: balanço crítico e perspectivas. Rio de Janeiro: Letra Capital: Observatório das Cidades: IPPUR/UFRJ, 2011.

SEABRA, Odette Carvalho de Lima. Urbanização e fragmentação: cotidiano e vida de bairro na metamorfose da cidade em metrópole a partir do bairro do Limão. São Paulo (2003). Tese de livre docência. Faculdade de Filosofia, Letras e Ciências Humanas/USP.

SEABRA, Odette Carvalho de Lima. Territórios do uso: Cotidiano e modo de vida. In: CIDADES. v. 1, n. 2, 2004, p. 181-206.

SPOSITO, Maria Encarnação Beltrão. Cidades médias e pequenas: as particularidades da urbanização brasileira. In: DIAS, Patrícia Chame, LOPES, Diva Maria Ferlin. Cidades médias e pequenas: desafios e possibilidades do planejamento e gestão. Salvador: SEI, 2014.

SOUZA, Marcelo Lopes de. ABC do desenvolvimento urbano. 6 ed. Rio de Janeiro: Bertrand Brasil, 2011.

VILLAÇA, Flávio. Uma contribuição para a história do planejamento urbano no Brasil. O Processo de urbanização no Brasil. São Paulo: Edusp, 2004.

Contribuição dos autores: James Amorim Araújo: Elaboração e desenvolvimento da pesquisa, Análise final dos resultados e revisão do texto. Djalma Villa Góis: Pesquisa e análise final dos resultados; revisão do texto. 